\title{
Entre escolas e hospitais: o desenvolvimento de crianças em tratamento hospitalar
}

\author{
Carmem Lucia Artioli Rolim* \\ http://dx.doi.org/10.1590/0103-7307201507806
}

\section{Resumo}

O presente estudo é resultado de pesquisa teórica que se propõe a discutir o hospital e a escola como espaços de desenvolvimento da infância acometida pelo câncer. Na abordagem do tema, são explorados as construções históricas da saúde e da doença e o desenvolvimento de crianças que necessitam de internações recorrentes, vivenciando os protocolos hospitalares e a sistematização escolar. De abordagem qualitativa, os procedimentos utilizados para o estudo compreenderam a pesquisa bibliográfica e documental, com o intuito de incorporar proposições do contexto histórico e cultural sobre os processos humanos, em especial os mais vinculados ao desenvolvimento infantil. Os resultados questionam o diálogo das instituições responsáveis pela criança em tratamento hospitalar e indicam a precariedade dessa relação, ao produzir uma educação marcada por impossibilidades, em que barreiras físicas e sociais se escondem sob a máscara da doença e fazem surgir na criança o gosto amargo do insucesso.

Palavras-chave: educação hospitalar, saúde e doença, desenvolvimento infantil

* Universidade Federal do Tocantins, Palmas, T0, Brasil. carmem.rolim@uft.edu.br 


\title{
Between schools and hospitals: the development of children undergoing hospital treatment
}

\begin{abstract}
This article presents the results of a study that explored the literature on hospital and school as spaces for the development of the children affected by cancer. Historical constructions of health and disease, and of the development of children requiring recurrent hospitalizations, thus experiencing hospital protocols and school systematization, are discussed. The results question the interaction between the two institutions responsible for the education of the child undergoing hospital treatment, indicating how precarious this relationship is, and how it produces an education marked by impossibilities, where physical and social barriers are hidden under the mask of the disease, allowing to arise a bitter taste of failure from the part of the child.
\end{abstract}

Keywords: hospital education, health and disease, child development 


\section{Introdução}

Pensar os espaços de atendimento educacional realizado às crianças com comprometimentos de saúde traz à tona questionamentos que acompanham o desenvolvimento da humanidade e remetem à reflexão sobre saúde e doença; vida e morte; habilidade e debilidade. Questões essas que, mesmo em aparente antagonismo, falam de um continuum e se tornam ainda mais complexas diante de patologias graves, como o câncer infantil, na medida em que o movimento do "estar doente" acaba por exigir uma troca quase absoluta das rotinas educacionais pelos protocolos ${ }^{1}$ médicos. Situação que substitui carteiras escolares por leitos hospitalares.

Nesse cenário, temos por propósito refletir sobre os espaços escolares e hospitalares, na relação com o processo de desenvolvimento da criança em tratamento de câncer. Para tanto, realizamos uma pesquisa, bibliográfica e documental, de abordagem qualitativa.

Pensamos o desenvolvimento de crianças com comprometimentos de saúde, associando a ideia de potencialidades, tomando como referência Góes (2007), Smolka (2008) e Vygotsky $(1997,2004)$. Para trazer a construção histórica de saúde-doença, caminhamos com Canguilhem (2000); e adentramos escolas e hospitais, por meio da infância comprometida pela doença com Foucault (2001), no intuito de incorporar proposições do contexto histórico e cultural sobre os processos humanos, em especial aos mais vinculados ao desenvolvimento da criança.

\section{Saúde e doença: múltiplas vozes}

Iniciamos o estudo pensando a saúde e a doença como processo constitutivo da vida. Canguilhem (2000) trata saúde-doença como movimento único, longe da visão dualista. 0 autor pontua interações entre estados saudáveis e doentios, vivências que dizem do próprio organismo, uma ação contínua, porém segmentada pelas expectativas sociais, fragmentações tecidas por crenças e valores que ultrapassam os limites da individualidade, construções forjadas pelas exigências da sociedade e edificadas nas concepções tecidas culturalmente.

Para o autor, viver com saúde é navegar na calmaria, mas, quando o futuro projetado está ameaçado pela doença, principalmente quando pode levar à morte, tem início um movimento de questionamento e busca, um estado de desequilí-

1. Para Lagioia, U. C. T., Ribeiro Filho, J. F., Falk, J. A., Libonati, J. J., \& Lopes, J. E. G. (2008) “Os protocolos representam uma sequência ótima de procedimentos, efetuados no tempo certo, ... contêm todas as atividades que serão realizadas nos pacientes que apresentem determinadas patologias em seus aspectos de promoção, prevenção, diagnóstico, tratamento, reabilitação e cuidados crôni$\cos ^{\prime \prime}$ (p. 80). 
brio no qual a doença pesa na balança, trazendo consigo um processo de hesitações e inconsistências. Nesse contexto, estar doente é mais que um processo orgânico, envolve a construção histórica da patologia, uma história marcada pelo tratamento e seus resultados. Esses resultados passam por um processo complexo de avaliação social, são respostas julgadas pelo meio, que demarcam os limites entre o normal e o patológico. Nas palavras do autor, "o meio social determina o que se chama doença" (Canguilhem, 2000, p. 93); mais que um processo biológico, é a sociedade que impõe às doenças os pesos diferenciados que desvalorizam o sujeito.

Deslocamos a doença de condição subjetiva para um estado patológico de apanhados de sintomas orgânicos, avaliados socialmente. 0 sujeito acometido pela patologia é julgado e passa a ser o resultado de sua doença, e como tal é nomeado; ocorre, então, a fusão entre doente e doença. 0 doente-doença assume um estado negativo, elo prejudicial ao grupo a que pertence, haja vista ele, doente-doença, carregar consigo as marcas do indesejável (Canguilhem, 2000).

O doente-doença perde seu lugar social, o ambiente "sadio" é agora substituído, o sujeito é deslocado ao "limbo", ao espaço revelador dos males humanos: o hospital. Para adentrar os espaços hospitalares, acompanhamos os pensamentos de Foucault (2001), que revela importante aspecto do hospital, espaço onde viver ou morrer não constitui o ponto principal, mas, sim, a transformação de dores em conhecimento, local onde protocolos são seguidos e testados, e emoções são racionalizadas como parte de resultados laboratoriais. 0 sujeito é então estigmatizado, perdendo, além do espaço conhecido, suas roupas e seus pertences; sobrepujado pela necessidade, acata o tratamento formatado por regras impessoais, suas fragilidades são mais acentuadas diante de precárias condições sociais e a esse tratamento o sujeito deve ser agradecido, posto the serem oportunizados a cura e o retorno à antiga condição social. Nas palavras de Foucault (2001),

Recusando-se a se oferecer como objeto de instrução, o doente se tornaria ingrato, pois teria usufruído das vantagens que resultam da sociabilidade sem pagar o tributo do reconhecimento. E, reciprocamente, delineia-se para o rico a utilidade de ajudar os pobres hospitalizados: pagando para tratá-los, pagará de fato, inclusive para que se conheçam melhor as doenças que podem também afetá-lo; o que é benevolência com respeito ao pobre se transforma em conhecimento aplicável ao rico: os dons benéficos vão mitigar os males do pobre, de que resultam luzes para a conservação do rico. Sim, ricos beneficentes, 
homens generosos, este doente que se deita no leito que para ele preparastes experimenta presentemente a doença que não tardareis a ser atacados; ele se curará ou perecerá; mas em um ou outro caso, sua sorte pode esclarecer vosso médico e vos salvar a vida (p. 96).

Adentrar os espaços hospitalares, à maneira de Foucault (2001), é abrir mão do olhar ingênuo que acalenta seus leitos; o local, antes encoberto pelo desejo de cura, revela o serviço que presta à sociedade: um espaço de afastamento das dores e da higienização social. Local propício para vivenciar a enfermidade não apenas como processo patológico, mas também como reconhecimento social da doença, uma realidade que demarca espaços e sujeitos, sendo esses, adultos ou crianças. Mas, ao olharmos especificamente para a criança doente, encontramos um agravante, o comprometimento de uma das principais fases do desenvolvimento humano: a infância. Adoecer na infância afeta a vida ainda em seu início; no caso de doenças crônicas, como o câncer, os efeitos são mais acentuados, para Castro e Piccinini (2002):

Cumprir com as tarefas próprias da infância e lidar com o estresse comum desta etapa se torna mais difícil para a criança enferma. A existência de sintomas dolorosos associados à doença crônica e as constantes avaliações e tratamentos podem alterar seu funcionamento físico e mental, bem como sua interação com o ambiente (p. 628).

Mesmo com os avanços nos tratamentos e a criação de inúmeras vacinas, muitas crianças são acometidas por doenças graves e necessitam de internações hospitalares. Para Ferrer (2009), vários são os motivos de internações recorrentes na infância, dentre eles, destacam-se infecções, hemorragias, doenças autoimunes, diarreia e doenças respiratórias, sendo que o principal responsável por internações, cujos períodos são prolongados e frequentes, são os casos de carcinoma. Quando o adoecer está relacionado ao câncer, os cuidados acatam protocolos de tratamentos rigorosos; o viver segue a rotina de exames, medicações e privações. Nas palavras de Nigro (2004), doenças exigem esforços físicos e psicológicos para a preservação da vida, e a fusão câncer e infância traça uma rota singular, embargada em sofrimentos; contexto esse que agride o mundo infantil não apenas pelo desconforto causado ao organismo, mas também pela agressão psicológica, na medida em que desloca a criança do espaço conhecido e acolhedor, local de múltiplas relações sociais, para um mundo monocromático e inóspito, território de restrições, o qual coloca em suspenso esferas do fazer cotidiano. 
O cotidiano roubado pelos protocolos hospitalares cobra uma rotina em que a escola se torna inacessível. Para Ortiz e Freitas (2005), a ruptura com a escola "significa a negação de estímulos de vida e o sepultamento de sua força motriz de inventividade: é a falência de seus processos de cognição e de sua humanização" (p. 42). Faria Filho (1998) pensa a escola como local, território delimitado de apropriações diversas, considerada como espaço necessário para o desenvolvimento dos sujeitos. Diante da valorização cultural do frequentar a escola, a criança significa o "estar" na escola como preparo para o futuro, e o afastamento escolar torna-se símbolo da desesperança.

0 desejo de frequentar a escola vem envolto em um mergulho na significação que a escola assume para o paciente. Ela representa um lugar de trânsito permitido de entradas e saídas, contrastando com o confinamento do hospital e, ainda, carregando uma aceitação social garantida pelas representações construídas pela sociedade de que, na escola, circulam os alunos "saudáveis" [ênfase no original]. É precisamente este signo de reconhecimento que o paciente, ... reclama para si ao ter de enfrentar o evento da internação (Ortiz \& Freitas, 2005, p. 47).

Nesse momento, significamos a parábola de Urals trazida por Leontiev (1978), em que, em situações de intenso sofrimento, a continuidade da caminhada é motivada não apenas pelas aprendizagens do passado ou pelo momento presente, mas pela perspectiva do futuro. Pensando na criança acometida pelo câncer, a qual de forma inesperada se surpreende no hospital, vemos o desafio que se apresenta para educadores, profissionais da saúde e familiares, posto essa criança manter na escola o significado de continuidade da vida. E, ao ser levada ao leito hospitalar, vivencia a saúde-doença com restrições que dizem do próprio organismo, como também de acesso ao seu grupo social. Nesse contexto, escolas e hospitais se encontram e exigem um esforço conjunto para ultrapassar limites e garantir o desenvolvimento de crianças hospitalizadas.

\section{Atendimento educacional: entre escolas e hospitais}

Pensar o atendimento educacional considerando crianças com comprometimentos de saúde é adentrar escolas e hospitais transitando por territórios distintos, separados pelos objetivos de sua criação, mas inter-relacionados pelos sujeitos que ocu- 
pam seus espaços. 0 ambiente escolar é parte da rotina infantil, e a hospitalização altera o mundo conhecido da criança. No caso específico do tratamento do câncer, o afastamento escolar é inevitável, mas permanece a necessidade de desenvolvimento, a aprendizagem e a garantia de qualidade de vida da criança. Nesse contexto, escolas e hospitais compartilham responsabilidades quanto ao público infantil, sendo necessário esforço social diante não apenas da debilidade orgânica, mas também do processo histórico da doença.

Pensar o processo histórico da patologia remete ao reconhecimento de que o julgamento social contabiliza resultados, e o câncer se destaca dentre as doenças. Seu nome foi, ao longo do tempo, associado aos óbitos² ${ }^{2}$ criando estigma capaz de sobrepujar as individualidades orgânicas e assumir o lugar do sujeito. Segundo Lopes, Camargo e Bianchi (2000), pelo próprio processo histórico da doença, o objetivo do tratamento, principalmente na década de 70 do século passado, era alcançar a cura, independentemente de possíveis sequelas, momento no qual "a maioria dos efeitos tardios não eram conhecidos, pois o período de observação pós-tratamento era pequeno e parte destes efeitos não eram ainda encontrados ou descritos na literatura" (p. 277).

Atualmente, o tratamento do câncer infantil evoluiu, e hoje, além da cura, há preocupação com a qualidade de vida, considerando-se os efeitos denominados tardios, os quais dizem respeito a debilidades causadas ao organismo, mas que só se manifestarão após certo período de tempo. No caso específico da criança, o tratamento envolve importante fase de desenvolvimento, tanto das funções orgânicas quanto das psicológicas.

Como Vygotsky (1997), consideramos o desenvolvimento resultado de um processo que extrapola parâmetros biológicos, e, à medida que a sociedade estabelece padrões, a não adequação do sujeito a esses padrões é considerada fora dos limites da "normalidade", situação que reflete segregação e sentimento de inferioridade. Dessa forma, considerar o desenvolvimento humano, além de causas biológicas, é buscar a totalidade, é vê-lo como processo que apresenta especificidades biológicas, porém influenciado socialmente.

Nesse contexto, a escola se apresenta como espaço privilegiado para o processo de desenvolvimento, nas palavras de Vygotsky (2001). Refletir sobre desenvolvimento é pensar em atividades educacionais, pois ambos não se desvinculam, eles caminham e se inter-relacio-

2. "As neoplasias malignas constituem-se na segunda causa de morte na população, representando quase $17 \%$ dos óbitos de causa conhecida", segundo o documento Estimativa 2010: incidência de câncer no Brasil, do Instituto Nacional do Câncer do Ministério da Saúde. 
nam, por vezes coincidem, porém cada qual a seu ritmo, e, em alguns casos, a aprendizagem se adianta ao desenvolvimento, "o fator principal que constitui o desenvolvimento é a instrução. ... Em idade infantil, somente é bom o ensino que se adianta ao desenvolvimento e o leva consigo" (Vygotsky, 1997, p. 241). Desenvolvimento e instrução são movimentos complexos, construções individuais, que ganham significado nas relações sociais, “assim, o aprendizado é um aspecto necessário e universal do processo de desenvolvimento das funções psicológicas culturalmente organizadas e especificamente humanas" (Vygotsky, 1989, p. 101).

O desenvolvimento infantil não caminha sozinho, no isolamento individual. A criança, ao se manifestar socialmente, recebe o retorno de seu comportamento. Nesse momento, suas atividades são significadas, manifestações individuais e sociais se autoconstroem.

Desde os primeiros dias do desenvolvimento da criança, suas atividades adquirem um significado próprio num sistema de comportamento social e, sendo dirigidas a objetivos definidos, são refratadas através do prisma do ambiente da criança. 0 caminho do objeto até a criança e desta até o objeto passa através de outra pessoa. Essa estrutura humana complexa é o produto de um processo de desenvolvimento profundamente enraizado nas ligações entre história individual e história social (Vygotsky, 1989, p. 33).

0 isolamento social afeta substancialmente o desenvolvimento humano, o viver com restrições provocadas por patologias exige intenso esforço individual e social. Nessa perspectiva, Góes (2007), retomando Vygotsky, pontua a importância do outro no desenvolvimento do sujeito. A autora destaca a plasticidade do psiquismo, matéria viva e potencializadora do desenvolvimento humano. Quando o grupo social é capaz de estimular a plasticidade, estará trabalhando com potencialidades, pois é esse o estímulo capaz de criar novos caminhos, ou seja, modificar a estrutura inicial para dar continuidade ao desenvolvimento.

Pensar o desenvolvimento de crianças com comprometimento de saúde, associado à ideia de potencialidade, tendo por referência Vygotsky $(1997,2004)$ e Góes (2007), é abrir outra perspectiva para a educação, uma dimensão que permite considerar o processo de ensino, desenvolvido em ambiente hospitalar como fortalecedor do núcleo vital saudável da criança. Trata-se, pois, de intricado processo resultante de manifestações da relação individual e social, movimentos que se entrelaçam e se 
transformam em possibilidades, em que o sujeito, antes segregado em sua diferença, vê como possível a sua permanência no grupo ao qual antes pertencia.

Esse processo indica que o desenvolvimento da criança doente vai além dos comprometimentos patológicos; depende, principalmente, da forma como a sociedade reage à situação. Vygotsky (1997) pontua o isolamento do grupo social e a falta de estímulo educacional como agentes de segregação, pois reduzir a criança à sua dificuldade é condená-la à exclusão; à medida que o grupo desiste da criança, está condenando-a ao conformismo, ao aceitar sem questionar. Góes (2007) chama a atenção para os agentes incapacitantes e destaca não serem os fatores biológicos os principais atores do processo, mas, sim, a resposta social dada às debilidades do organismo. É a sociedade deficiente que molda o tamanho dos obstáculos impostos para as crianças hospitalizadas. Nessa perspectiva, escolas e hospitais precisam assumir suas responsabilidades, o que se efetivará como direito, ao ser amparado por parâmetros legais.

\section{Parâmetros legais: dilemas e direitos}

0 atendimento escolar para crianças hospitalizadas, em território brasileiro, ocorre desde 1950, porém o crescimento é paulatino e insuficiente para atendimento das crianças em tratamento hospitalar. Para Fonseca (1999, 2002), o atendimento educacional hospitalar começou a ganhar espaço somente após 40 anos da institucionalização da primeira classe hospitalar, quando, em 1990, o número de classes de atendimento escolar para pacientes chegou a 39, funcionando em 30 hospitais, 11 deles infantis. Segundo Censo do Inep (2013), atualmente estão cadastradas 47 escolas de ensino regular e especial que oferecem classes hospitalares para turmas

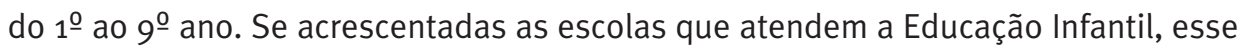
número atinge o total de 50 escolas. É possível que os números sejam um pouco maiores, pois algumas escolas indicaram, em seu censo, apenas a educação especial, sem diferenciar a turma hospitalar, o que dificulta a exatidão dos dados. Segundo Rolim (2008), "essas classes resultaram de uma proposta da Sociedade Brasileira de Pediatria, acolhida pelo Conselho Nacional dos Direitos da Criança e do Adolescente (Conanda), que levou à promulgação dos Direitos da Criança e do Adolescente Hospitalizados (Resolução no. 41, de 13/10/1995)” (p. 17).

São classes que, ao serem implantadas, visam garantir o direito à educação, como instituído pela Constituição Federal: 
Art. $6^{\circ}$ São direitos sociais a educação, a saúde, a alimentação, o trabalho, a moradia, o lazer, a segurança, a previdência social, a proteção à maternidade e à infância, a assistência aos desamparados, na forma desta Constituição. (EC no 26/2000 e EC no 64/2010).

Art. 205. A educação, direito de todos e dever do Estado e da familia, será promovida e incentivada com a colaboração da sociedade, visando o pleno desenvolvimento da pessoa, seu preparo para o exercício da cidadania e sua qualificação para o trabalho.

Direito presente, também, nas Diretrizes Nacionais para a Educação Especial na Educação Básica - Resolução no 2, de 11 de setembro de 2001; do Conselho Nacional de Educação; e no documento Classe Hospitalar e Atendimento Pedagógico Domiciliar, elaborado pela Secretaria de Educação Especial (SEESP/MEC), em dezembro de 2002, que visa "estruturar ações políticas de organização do sistema de atendimento educacional em ambientes hospitalares e domiciliares", reconhecendo a educação como exercício de cidadania e qualificação para o trabalho, sendo sua promoção de responsabilidade do Estado e da família. Um direito institucionalmente constituído e, se descumprido, passível de punição, como observado na Constituição da República Federativa do Brasil:

Art. 208. 0 dever do Estado com a educação será efetivado mediante a garantia de: (EC no 14/96, EC no 53/2006 e EC no 59/2009)

I - educação básica obrigatória e gratuita dos 4 (quatro) aos 17 (dezessete) anos de idade, assegurada inclusive sua oferta gratuita para todos os que a ela não tiveram acesso na idade própria;

VII - atendimento ao educando, em todas as etapas da educação básica, por meio de programas suplementares de material didático- -escolar, transporte, alimentação e assistência à saúde.

$\S 2^{\circ} 0$ não oferecimento do ensino obrigatório pelo Poder Público, ou sua oferta irregular, importa responsabilidade da autoridade competente.

Para que o atendimento às crianças hospitalizadas se normalizasse, o Ministério 
da Educação, por meio da Secretaria de Educação Especial, elaborou o documento Classe hospitalar e atendimento pedagógico domiciliar: estratégias e orientações, que orienta para o atendimento de crianças e adolescentes em tratamento hospitalar. Essas orientações tratam do atendimento em ambiente hospitalar e o atendimento pedagógico domiciliar.

$\mathrm{O}$ atendimento domiciliar consiste em oferecer apoio didático-pedagógico no ambiente de moradia da criança, com vistas a propiciar a construção do conhecimento para alunos regularmente matriculados nos sistemas de ensino, mas impossibilitados de frequentar temporariamente as escolas. 0 atendimento hospitalar ocorre no espaço de tratamento da saúde, seja em enfermarias, ambulatórios, leitos, ou mesmo em locais adaptados pelo hospital para atividades escolares, denominado de classe hospitalar. Esse deve ser implantado pela necessidade de internação da criança e afastamento escolar, por um dia ou por longo período de tempo.

0 alunado das classes hospitalares é aquele composto por educandos cuja condição clínica ou cujas exigências de cuidado em saúde interferem na permanência escolar ou nas condições de construção do conhecimento ou, ainda, que impedem a frequência escolar, temporária ou permanente. ... 0 alunado do atendimento pedagógico domiciliar compõe-se por aqueles alunos matriculados nos sistemas de ensino, cuja condição clínica ou exigência de atenção integral à saúde, considerados os aspectos psicossociais, interfiram na permanência escolar ou nas condições de construção do conhecimento, impedindo temporariamente a frequência escolar.

Pela legislação vigente, observamos que a criança em tratamento hospitalar, quando impossibilitada de frequentar a escola, tem o direito de continuar seu processo educacional independentemente do local em que se encontre, ou do tempo de afastamento. Negar essa possibilidade é violar o direito ao desenvolvimento pleno, negligenciando a atenção integral à criança. Segundo Silva, Gallego e Teixeira (2006), o direito ao estudo é fundamental, porém, para a criança que vivencia patologias, a atividade escolar torna-se essencial. Os efeitos dos laços escolares trazem melhorias no desenvolvimento e na qualidade de vida por refletirem a esperança no futuro. Nas palavras das autoras, a educação escolar é capaz de “dispersar a perspectiva de morte” (p. 35).

Pensar a educação escolar como fundamental para o desenvolvimento infantil em nossa sociedade é reafirmar a importância da classe hospitalar, mas instituir, de 
fato, o que já foi garantido como direito é movimento complexo, exige aproximações onde antes só existia isolamento, ou seja, um processo de transformação nos espaços delimitados por barreiras sociais. Segundo Santos (2008, p. 16), instituir um espaço é edificar algo que resiste, protege, guarda o vigor de uma cultura. Trazendo os pensamentos de Canguilhem (2000), vemos que quebrar a hegemonia dos leitos hospitalares com livros escolares é também incutir uma fenda nas normas que ditam o normal. É edificar a escola onde só existia a doença, uma tentativa de garantir o direito da criança de manter seu lugar de aluno entre alunos. Transformar os limites hospitalares por meio da educação escolar envolve rupturas na hierarquização de um processo normativo mantido por justificativas biológicas. Porém, Silva (2000) revela que atitudes aparentemente baseadas em argumentos biológicos são, na realidade, construções sociais. "As chamadas interpretações biológicas são, antes de serem biológicas, interpretações, isto é, elas não são mais do que a imposição de uma matriz de significação sobre uma matéria que, sem elas, não tem significado ... São assim culturais" (p. 86).

É importante destacar que não desconsideramos os fatores biológicos que influenciam a vida do sujeito; pelo contrário, é no reconhecimento das fragilidades orgânicas que se torna possível conceber a educação que investe nas potencialidades. Esse movimento de conexão entre escolas e hospitais permite transformar territórios e gerar novos espaços, uma interconexão em que a totalidade do sujeito é pensada.

\section{Para não concluir...}

Diante das considerações apresentadas, é possível constatar que o desequilíbrio orgânico, provocado por uma doença que exige períodos de internação, traz limitações dos espaços físicos e sociais. Esse processo é particularmente agressivo quando atinge a infância, por restringir as oportunidades educacionais no principal período do desenvolvimento do sujeito. Como indicado anteriormente, o Brasil possui leis que regulamentam o direito à educação para todos, o que inclui crianças em tratamento hospitalar, seja por meio do acompanhamento domiciliar ou das classes hospitalares, porém sua implantação ainda é insuficiente.

Falamos de direitos adquiridos e dilemas para sua efetivação, obstáculos que se constituem no momento presente, e cujas origens são anteriores às da implantação da primeira classe hospitalar, processo que envolve a construção histórica da doen- 
ça. O desenvolvimento educacional para crianças hospitalizadas exige mudanças socioculturais de uma sociedade que criou estratégias de isolamento das misérias humanas, estigmatizou o doente em sua doença, de forma que esse doente deveria ser envolvido, fracionado, isolado. “Um grupo, para manter e se proteger, pratica exclusões, estabelece as formas de assistência, reage ao medo da morte, recalca ou alivia a miséria, intervém nas doenças ou as abandona a seu curso natural” (Foucault, 2001, p. 16). 0 mesmo grupo que colocou o doente-doença na higienização hospitalar mantém na escola o símbolo da vida, da continuidade. Efetivar a relação escola-hospital possibilita a ruptura da situação social vigente, é movimento que vai além do rompimento de fronteiras, ele inaugura um novo espaço, construído entre os leitos hospitalares e as mesas escolares, capaz de revelar as necessidades de minorias, no caso uma minoria doente e silenciosa, oculta nos leitos dos hospitais, invisível a uma sociedade sadia.

Reiteramos nossa fala, ao indicar a importância do diálogo entre ambos os espaços, escola e hospital, porém sua integração é mais desafiadora do que sugere a legislação, por envolver não apenas fatores biológicos, mas também construção histórica, social e cultural. Garantir espaços de atendimento educacional às crianças com comprometimentos de saúde é, além de direito, uma necessidade. Negá-lo é manter a situação social vigente, impondo uma educação marcada por impossibilidades a qual faz surgir o gosto amargo do insucesso.

Como Góes e Smolka (2008), consideramos, ao possibilitar atendimento educacional, estar caminhando com as potencialidades, pois, ao estimular a aprendizagem, impulsionamos o desenvolvimento da criança, mas é Vygotsky (1997) quem cobra a responsabilidade de a sociedade garantir o desenvolvimento educacional da criança, pois somente por meio do trabalho do grupo social é possível unir espaços que a própria sociedade, escondida na sombra da doença, separou. Nesse momento, colocamos a necessidade de continuidade das discussões, destacando a importância tanto dos profissionais da educação como dos da saúde, pois eles não podem permanecer omissos da responsabilidade que também lhes pertence, e, à maneira de Leontiev (1978), eles devem possibilitar às crianças, em tratamento de câncer, o levantar a cabeça e o olhar além. 25 de setembro de 2014. 


\section{Referências bibliográficas}

Canguilhem, G. (2000). O normal e o patológico. Rio de Janeiro: Forense Universitária.

Castro, E. K. de, \& Piccinini, C. A. (2002). Implicações da doença orgânica crônica na infância para as relações familiares: algumas questões teóricas. Psicologia: Reflexão e Crítica, 15(3), 625-635.

Faria Filho, L. M. (1998, janeiro/junho). O espaço escolar como objeto da história da educação: algumas reflexões. Revista da Faculdade de Educação, 24(1), 141-159. Retirado em 13 de abril de 2013, de < http://www.scielo.br/scielo.php?pid=So10225551998000100010\&script $=$ sci_arttext $>$.

Ferrer, A. P. S. (2009). Estudo das causas de internação hospitalar das crianças de o a 9 anos de idade. 144f. Dissertação de Mestrado em Ciências, Faculdade de Medicina da Universidade de São Paulo, São Paulo.

Fonseca. E. S. (1999, junho). A situação brasileira do atendimento pedagógicoeducacional hospitalar. Educação e Pesquisa, 25(1), 117-129.

Fonseca, E. S. (2002, julho/dezembro). Implantação e implementação de espaço escolar para crianças hospitalizadas. Revista Brasileira de Educação Especial, 8(2), 205-222. Retirado em 12 de setembro de 2012, de < http://www.abpee.net/ homepageabpeeo4_06/artigos_em_pdf/revista8numero2pdf/5fonseca.pdf〉.

Foucault, M. (2001). O nascimento da clínica. Rio de Janeiro: Forense Universitária.

Góes, M. C. R. de. (2007). Contribuições da abordagem histórico-cultural nas pesquisas em educação especial. In III Seminário de Pesquisa em Educação especial: diálogo e pluralidade. São Paulo, SP: ABPEE.

Góes, M. C. R. de, \& Smolka, A. L. B. (2008). A linguagem e o outro no espaço escolar: Vygotsky e a construção do conhecimento. Campinas: Papirus.

Lagioia, U. C. T., Ribeiro Filho, J. F., Falk, J. A., Libonati, J. J., \& Lopes, J. E. G. (2008, dezembro). A gestão por processos gera melhoria de qualidade e redução de custos: o caso da unidade de ortopedia e traumatologia do hospital das clínicas da Universidade Federal de Pernambuco. Revista Contabilidade Financeira, 19(48), 77-90.

Leontiev, A. N. (1978). Atividade consciência e personalidade. (M. S.C. Martins, trad.). Retirado em 19 de março de 2013, de <http://www.marxists.org/portugues/ leontiev/1978/activ_person/index.htm>.

Lopes, L. F., Camargo, B. de, \& Bianchi, A. (2000, julho/setembro). Os efeitos tardios do tratamento do câncer infantil. Revista da Associação de Medicina do Brasil, 46(3), 277-284. 
Nigro, M. (2004). Hospitalização: o impacto na criança, no adolescente e no psicólogo hospitalar. São Paulo: Casa do Psicólogo.

Ortiz, L. C. M., \& Freitas, S. N. (2005). Classe hospitalar: caminhos pedagógicos entre saúde e educação. Santa Maria: UFSM.

Rolim, C. L. A. (2008). A criança em tratamento de câncer e sua relação com o aprender: experiências num programa educacional em ambiente hospitalar. 202f. Tese de Doutorado em Educação, Universidade Metodista de Piracicaba, Piracicaba.

Santos, M. (2008). Técnica, espaço, tempo: globalização e meio técnico-científicoinformacional. São Paulo: EDUSP.

Silva, A. M., Gallego, E. T., \& Teixeira, M. C. T. V. (2006, junho). Habilidades intelectuais de crianças com câncer e crianças não portadoras da doença. Avaliação Psicológica, 5(1), 33-41.

Silva, T. T. (2000). Identidade e diferença: a perspectiva de estudos culturais. Petrópolis, RJ: Vozes.

Smolka, A. L. B. (2008). A dinâmica discursiva no ato de escrever relações oralidadeescritura. In M. C. R. Góes, \& A. L. B. Smolka (Org.), A linguagem e o outro no espaço escolar: Vygotsky e a construção do conhecimento (pp. 33-62). Campinas: Papirus.

Vygotsky, L. S. (1989). Formação social da mente. São Paulo: Martins Fontes.

Vygotsky, L. S. (1997). Fundamentos de defectología. (Obras escogidas, Vol. 5). Madri: Visor.

Vygotsky, L. S. (2001). A construção do pensamento e da linguagem. São Paulo: Martins Fontes.

Vygotsky, L. S. (2004). Psicologia pedagógica. São Paulo: Martins Fontes.

\section{Legislação}

Resolução CNE/CEB 2/2001. Conselho Nacional de Educação. Câmara de Educação Básica Diário Oficial da União, Brasília, DF, 14 set. 2001. Seção 1E, pp. 39-40.

Classe hospitalar e atendimento pedagógico domiciliar: estratégias e orientações. Secretaria de Educação Especial. Brasília: MEC ; SEESP, 2002.

Constituição da República Federativa do Brasil: texto consolidado até a Emenda constitucional nํ. 64, de 04 de fevereiro de 2010. Brasília: Senado Federal, 2010. Retirado em 13 de fevereiro de 2013, de 〈http: www.senado.gov.br/sf/legislacao/ const/>. 
Estimativa 2010: incidência de câncer no Brasil. Instituto Nacional de Câncer. Ministério da Saúde. Rio de Janeiro: INCA.

Censo Inep - 2013. Instituto Nacional de Estudos e Pesquisas Educacionais Anísio Teixeira. Censo Nacional da Educação Básica. Diário Oficial da União. Brasília, DF, 30 de dezembro de 2013. Seção I, p. 860.

Submetido à avaliação em 7 de fevereiro de 2014; aprovado para publicação em 25 de setembro de 2014. 